\title{
Erratum to: Pain Management in Patients with Cancer: Focus on Opioid Analgesics
}

\author{
Wojciech Leppert
}

Published online: 31 August 2011

(C) Springer Science+Business Media, LLC 2011

Erratum to: Curr Pain Headache Rep 2011, 15(4):271-79

DOI 10.1007/s11916-011-0201-7

Leppert W: Pain Management in Patients with Cancer. Curr Pain Headache Rep 2011, 15:271-79.

This article was published in the August 2011 issue of Current Pain and Headache Reports (volume 15, issue 4). The author has found an error in the "Fentanyl" section. On page 274, the following sentence is incorrect: "There are five types of patches that release $12,25,50,75$, and $100 \mu \mathrm{g} / \mathrm{h}$ equal to $2.1-, 4.2-, 8.4-, 12.6-$, and $16.8-\mathrm{mg}$ fentanyl dose per day, respectively."

The author has provided this corrected text: There are five types of patches that release $12,25,50,75$, and $100 \mu \mathrm{g} / \mathrm{h}$, equal to about 0.3-, 0.6-, 1.2-, 1.8-, and 2.4-mg fentanyl dose per day, respectively.

The online version of the original article can be found at http://dx.doi. org/10.1007/s11916-011-0201-7.

W. Leppert $(\bowtie)$

Chair and Department of Palliative Medicine,

Poznan University of Medical Sciences,

Osiedle Rusa 25 A,

61-245 Poznan, Poland

e-mail: wojciechleppert@wp.pl 